\section{RMD Open}

Rheumatic \&

Musculoskeletal Diseases

\title{
Costs of early spondyloarthritis: estimates from the first 3 years of the DESIR cohort
}

Stephanie Harvard, ${ }^{1,2,3}$ Daphne Guh, ${ }^{2}$ Nick Bansback, ${ }^{2,3}$ Pascal Richette, ${ }^{4,5}$ Maxime Dougados, ${ }^{6,7,8,9}$ Aslam Anis,, ${ }^{1,2}$ Bruno Fautrel ${ }^{3,10}$

To cite: Harvard S, Guh D, Bansback N, et al. Costs of early spondyloarthritis: estimates from the first 3 years of the DESIR cohort. RMD Open 2016:2: 0000230 . doi:10.1136/rmdopen-2015000230

- Prepublication history and additional material is available. To view please visit the journal (http://dx.doi.org/ 10.1136/rmdopen-2015000230).

Received 17 December 2015 Revised 11 March 2016 Accepted 13 March 2016

CrossMark

For numbered affiliations see end of article.

Correspondence to Dr Stephanie Harvard; harvards@mail.ubc.ca

\section{ABSTRACT}

Objectives: To value health resource utilisation and productivity losses in DESIR, a longitudinal French cohort of 708 patients with early spondyloarthritis (SpA) enrolled between 2007 and 2010, and identify factors associated with costs in the first 3 years of follow-up.

Methods: Self-reported clinical data from DESIR and French public data were used to value health resource utilisation and productivity losses in 2013 Euros.

Factors associated with costs, including and excluding biological drugs, were identified in generalised linear models using the generalised estimating equations algorithm to account for repeated observations over participants.

Results: The mean $( \pm S D)$ annual cost per patient was $€ 5004 \pm 6870$ in year 1 , decreasing to $€ 4961 \pm 7457$ in year 3. Patients who never received a biologic had mean 3-year total costs of $€ 4789 \pm 6022$ compared to $€ 38206 \pm 19829$ among those who received a biologic Factors associated with increased total costs were peripheral arthritis (rate ratio (RR) $1.19 ; 95 \% \mathrm{Cl} 1.04$ to $1.37 ; p<0.0001$ ), time on biologics (RR 1.23 per month; $1.21,1.24 ; p<0.0001$ ), and average BASFI score (RR 1.18/10 point increase; 1.15, 1.25; $p<0.0001)$. Factors associated with increased costs excluding biologics were baseline age (RR 1.10 per 5 year increase; $1.05,1.16 ; p<0.0001)$, peripheral arthritis (RR 1.20; 1.02, 1.40; $p<0.0133$ ), time on biologics (RR 1.04 per month; 1.02, 1.05; $p<0.0001$ ), and average BASDAI score (RR 1.21 per 10 point increase; 1.16, 1.25; $p<0.0001$ ).

Conclusions: In addition to biologics, factors like age, peripheral arthritis and disease activity independently increase SpA-related costs. This study may serve as a benchmark for cost of illness among patients with early SpA in the biologic era.

\section{INTRODUCTION}

Spondyloarthritis (SpA) is a family of chronic rheumatic diseases that includes ankylosing spondylitis (AS), psoriatic spondyloarthritis (PsA), reactive SpA, SpA with inflammatory

\section{Key messages}

What is already known about this subject?

- Spondyloarthritis leads to healthcare costs as well as productivity loss, the latter having been shown to be the most significant cost driver. However, there is a lack of cost-of-illness studies among patients with early SpA in the biologics era.

What does this study add?

- In the biologic era, medication is the greatest cost driver among patients with SpA, exceeding productivity loss. Other factors like age, peripheral arthritis and functional ability are independently associated with total costs. In a cohort of patients with early SpA using biologics for less than 3 years, biologic use was associated with increased costs outside of biologics.

How might this impact on clinical practice?

- This study identifies factors associated with SpA-related costs in the biologic era, potentially pointing towards priority areas for biologics use and providing a new benchmark for cost of illness among patients with early SpA.

bowel disease and undifferentiated SpA. ${ }^{1}$ In its early phases, $\mathrm{SpA}$ is often undifferentiated, and corresponds to the concept of inflammatory back pain (IBP), the key feature of the disease. ${ }^{2}$ To date, most economic studies of SpA have examined outcomes among patients with AS or PsA specifically, and have not included patients with other SpA subtypes or with early SpA symptoms that are still evolving. A severe form of SpA, AS has been shown to cause significant pain, functional disability and loss of mobility ${ }^{3}$ In turn, these physical outcomes are associated with substantial health resource utilisation and work productivity loss among patients with $\mathrm{AS}^{45}$ 
In 2012, a systematic review identified 15 economic studies of SpA conducted worldwide since 2002, nine of which evaluated health resource utilisation and work productivity loss. The median cost of health resource utilisation in 2012 US dollars was $\$ 3764$ per patient per year, compared to a median cost of productivity loss of \$4999. ${ }^{6}$ More recently, biological TNF blockers have been made available for the treatment of moderate to severe SpA, increasing the cost of illness compared to previous years in which non-steroidal anti-inflammatory drugs (NSAIDs) were the only available drug therapy. ${ }^{7}$

The objective of this study was to value health resource utilisation and productivity losses among patients in the DESIR cohort, ${ }^{8}$ a longitudinal, multicentre study of early SpA in France. We further aimed to determine factors associated with total costs and with costs excluding biologics ('non-biologic costs') among DESIR patients.

\section{METHODS}

\section{Participants}

The DESIR cohort $^{9}$ includes 708 patients aged $18-50$ with early IBP lasting more than 3 months but less than 3 years, and suggestive of $\mathrm{SpA}$ according to the rheumatologists' assessment (score $\geq 5$ on a $0-10$ Numerical Rating Scale where $0=$ not suggestive and $10=$ very suggestive). Patients were required to fulfil the Calin $^{10}$ or Berlin ${ }^{11}$ IBP criteria. Patients with a definitive diagnosis of non-SpA back pain, a history of previous biological TNF-blocker use, or conditions that could affect informed consent and/or compliance (eg, alcoholism, psychiatric disorders) were excluded. All patients attended their baseline study visit between October 2007 and May 2010. Follow-up visits collecting self-report questionnaire data occurred every 6 months in the first 2 years and every year thereafter, and covered the health resource use since the previous visit. Our analyses included the first 3 years of follow-up, that is, baseline plus follow-up visits at months $6,12,18,24,36$. Data up to month 12 were from the DESIR database locked in February 2014, and data from months 18 to 36 from that locked in April 2015.

\section{Costing methods}

Our analysis estimated the total cost from the societal perspective (all payers combined) of all-cause health resource utilisation, specifically health practitioner visits, hospitalisations (including emergency room visits and surgeries), medical workups, and medications), and work productivity losses. Although we aimed to include as many societal costs as possible, other patient out-of-pocket costs (eg, transportation, devices, caregiver expenses and other costs sometimes termed 'nonmedical') were not included.

\section{Valuing health resource use}

Detailed costing methods are described in online supplementary tables S1-S4. Unit costs for health practitioner visits were estimated by adding base tariffs from the French National Health Insurance ${ }^{12}$ to the average cost of extra billings based on data from the IRDES (Institut de Recherche et de Documentation en Economie de la Santé) ${ }^{13}$ Eco-Santé database. ${ }^{14}$ Data on medical workups included laboratory analyses on blood and urine and functional/diagnostic tests. On the basis of clinical expertise, the cost of blood tests was estimated assuming the following standard laboratory analyses among patients with $\mathrm{SpA}$ : erythrocyte sedimentation rate (ESR); C-reactive protein (CRP); haemogram including platelets; thrombocytes; transaminases; creatinine; and creatinine clearance. Blood collection was valued at 15 min of nurse care; the unit cost of blood tests was the cost of analysis plus the cost of collection as per the French public insurance fee schedule. Urine tests were assumed to include urine protein only and no collection fee was applied. The following tests were attributed a single standard cost: mammography, MRI, bone densitometry, scintigraphy, respirometry, colonoscopy and fibroscopy. For X-rays, ultrasounds, scans and 'other exams', free-text data were reviewed individually and assigned specific examination codes which were linked to unit costs.

Data on medications included NSAIDs, DMARDs (conventional synthetic-csDMARDs-or biologicbDMARD), corticosteroids (oral, intramuscular, intra-articular and intravenous) and analgesics. For abatacept, infliximab and certolizumab, prices per milligram were derived from list prices in France using the Vidal dictionary. ${ }^{15}$ For all other drugs, cost data from the French public drug program ${ }^{16}$ were used to derive a price per milligram for each drug. Drugs were valued by multiplying price per milligram by number of milligrams per day by number of days of use (except injectable corticoids, which were valued by multiplying price per milligram by number of milligrams in the reported number of injections). Where dose data were missing, standard dosages were imputed taking into account the patient's weight where applicable. For infliximab only, a standard cost for administration in day hospital was applied every 6 weeks for the duration of the therapy.

Data on hospitalisations were assigned a diagnosis or act code and linked to Diagnosis-Related Group (DRG) codes using 2012 data from the French national agency for hospital information (ATIH, 'Agence Technique de l'Information sur l'Hospitalisation'). ${ }^{17}$ Selected DRG were then linked to costs using 2012 ATIH data. ${ }^{18}$ The base-case analysis used the 6-digit DRG selected as the best fit; sensitivity analyses were performed using DRG sharing the same first five digits as the best-fit DRG (see online supplementary table S3). All unit costs were adjusted to 2013 Euros based on the Consumer Price Index ${ }^{19}$ and multiplied by frequency of use.

\section{Valuing work productivity loss}

Data on patients' profession were collected in eight categories (table 1 ). Average daily wage data were obtained 
Table 1 Baseline characteristics of the DESIR cohort

\begin{tabular}{|c|c|c|}
\hline & \multicolumn{2}{|c|}{ All $(n=708)$} \\
\hline & Count & $\begin{array}{l}\text { Per } \\
\text { cent }\end{array}$ \\
\hline \multicolumn{3}{|l|}{ Age, sex, ethnicity } \\
\hline Age group $<25$ & 133 & 18.8 \\
\hline Age group $\geq 25$ and $<55$ & 572 & 80.1 \\
\hline Age group $\geq 50$ & 3 & 0.4 \\
\hline Male & 327 & 46.2 \\
\hline Caucasian & 634 & 89.6 \\
\hline \multicolumn{3}{|l|}{ Highest level of education } \\
\hline High school or less & 286 & 40.4 \\
\hline Post-secondary school & 418 & 59 \\
\hline \multicolumn{3}{|l|}{ Profession* ${ }^{*}$} \\
\hline Agriculturer & 6 & 0.9 \\
\hline $\begin{array}{l}\text { Artisan, retailer or small business } \\
\text { owner }\end{array}$ & 35 & 4.9 \\
\hline Executive or academic & 151 & 21.3 \\
\hline Intermediate professional & 54 & 7.7 \\
\hline Employee & 299 & 42.6 \\
\hline Tradesperson & 64 & 9 \\
\hline Without professional occupation & 93 & 13.3 \\
\hline \multicolumn{3}{|l|}{ Clinical characteristics } \\
\hline Early onset (<17 years) & 13 & 1.8 \\
\hline Late onset ( $>44$ years) & 72 & 10.2 \\
\hline $\begin{array}{l}\text { Presence of extra-articular } \\
\text { manifestations }\end{array}$ & 188 & 26.6 \\
\hline Uveitis & 60 & 8.5 \\
\hline Psoriasis & 112 & 15.8 \\
\hline Crohn's disease & 18 & 2.5 \\
\hline HLA B27 positive & 410 & 57.9 \\
\hline ASAS criteria (total): positive & 486 & 68.6 \\
\hline ASAS clinical criteria: positive & 404 & 57.1 \\
\hline ASAS imaging criteria: positive & 286 & 40.4 \\
\hline Clinical values & Mean & SD \\
\hline Disease duration in years & 1.5 & 0.9 \\
\hline $\begin{array}{l}\text { Physician's assessment of disease } \\
\text { activity }(0-10)\end{array}$ & 4.3 & 2.2 \\
\hline BASDAI score $(0-100)$ & 44.7 & 20 \\
\hline BASFI score $(0-100)$ & 30.4 & 22.8 \\
\hline
\end{tabular}

*Per cent values do not total 100 due to missing baseline data. ASAS, the Assessment of SpondyloArthritis international Society.

from the French Ministry of Agriculture ${ }^{20}$ and from the French National Institute of Statistics and Economic Studies ('INSEE'). ${ }^{20}$ Productivity loss was valued by multiplying the number of self-reported workdays lost per period by the average daily wage by professional category over the entire population of French workers as estimated by these public data sources. The age and sex distribution of the DESIR cohort was compared to that of the population of French workers from which average daily wages were obtained and wages were not further adjusted for age and sex.

\section{Handling missing clinical and cost data}

Missing cost and clinical data were imputed using the Monte Carlo Markov Chain (MCMC) multiple imputation procedure, the last observation carried forward
(LOCF) method, probabilistic imputation, or with negative values based on clinical expertise. Specifically, for clinical variables in which fluctuations are normal and commonly observed clinically (ie, ASDAS-CRP, BASDAI, BASFI and HAQ), missing data were handled with MCMC imputation, which was considered the best strategy for representing this variability. For clinical variables observed to have greater stability, either the LOCF method or probabilistic imputation was used in lieu of MCMC imputation, as these methods provide better control over the variability of values imputed; LOCF was used if all patients had baseline data, while probabilistic imputation was used if baseline data were missing. The imputation model is described in detail in the online supplementary appendix.

\section{Statistical analyses}

Patient characteristics were described by the mean \pm SD or number $(\%)$ at baseline. For descriptive purposes, patients were divided into four subsets based on imaging status: X-ray damage only; MRI inflammation only; X-Ray damage and MRI inflammation; neither. Costs of health resource utilisation and productivity losses were expressed as yearly costs. For health resource utilisation, year 1 costs were the sum of costs reported at months 6 and 12; year 2 costs were the sum of costs reported at months 18 and 24; year 3 costs were those reported at month 36 . For productivity losses, yearly costs were those reported at the 12-month, 24-month and 36-month visits. Yearly costs were described by the median and mean \pm SD.

To describe factors associated with annual total costs and non-biologic costs over the 3 years, we used generalised linear models with a $\gamma$ distribution of $\log \operatorname{link}$ and a generalised estimating equations algorithm to account for repeated measures within participants. The independent variables year, baseline age and sex were chosen to be included in all models throughout development. Other independent variables of interest included baseline education; profession; presence of peripheral arthritis at baseline; DESIR study centre; number of months on biologics; baseline imaging status; baseline BASDAI and BASFI values; and mean BASDAI and BASFI values (where year 1 mean=mean of months 0,6 , 12; year 2 mean=mean of months 12, 18, 24; and year 3 mean=mean of months 24, 36). At the outset, baseline and mean BASDAI and BASFI values were tested for collinearity and examined alone and together in models. Goodness of fit assessed by the quasi-likelihood statistic (QIC) was used to compare the model fit among models with various BASDAI and BASFI values (baseline, mean, or baseline and mean together). ${ }^{21-23}$ The model with the best fit was chosen for inclusion in subsequent models. All other independent variables of interest were examined separately in models adjusting for year, age and sex, and variables associated with the outcome at $\mathrm{p}<0.20$ were selected for inclusion in subsequent models. Model selection was then done in a 
backward stepwise manner, beginning with all variables and removing those that were not associated with the outcome at $p<0.05$ to increase goodness of fit based on the QIC. All analyses were performed using SAS 9.4.

\section{RESULTS}

\section{Patient characteristics}

At baseline, the mean age of patients was $33.7 \pm 8.6$ years and mean disease duration was $1.5 \pm 0.8$ years. Just under half of the patients were male $(46.2 \%)$ and the majority were Caucasian $(89.6 \%$ ) (table 1). Most patients were HLA-B27-positive $(57.9 \%)$. The mean BASDAI score (on $100)$ at baseline was $44.7 \pm 20.0$ and the mean BASFI score was $30.5 \pm 22.8$. The most common extrarheumatological manifestations were psoriasis $(15.8 \%)$ and uveitis $(8.5 \%)$. At baseline, 286 patients satisfied the Assessment of SpondyloArthritis international Society (ASAS imaging criteria $(40.4 \%)$ and 404 the ASAS clinical criteria $(57.1 \%)$; 486 patients satisfied one or the other $(68.6 \%)$. Table 1 shows the characteristics of patients by imaging status, that is, X-ray damage alone (7.2\%), MRI inflammation (13.8\%); X-ray damage and MRI inflammation (18.6\%), neither (56.9\%); a total of 24 patients had no data available to describe imaging status. Attendance at follow-up visits declined over time: of the 708 patients enrolled at baseline, 704 attended the 6-month visit, 698 the 12-month visit, 691 the 18-month visit, 692 the 24-month visit, and 631 the 36-month visit.
Costs

Health resource utilisation

Table 2 shows the estimated costs of health resource utilisation and productivity losses among all DESIR patients over 3 years. Medication was the largest cost component in all years, representing over $50 \%$ of all costs in all years. The absolute mean cost of medication increased from $€ 2680.2 \pm 5339.6$ in year 1 to $€ 3339.2 \pm 6224.1$ in year 2 to $€ 3396.3 \pm 6476.5$ in year 3 . The proportion of patients incurring costs from biologics was approximately a quarter each year. The cost of biologics accounted for approximately $95 \%$ of medication costs each year.

Health practitioner visits, the second largest cost component of health resource utilisation in all years, declined from $€ 733.2 \pm 788.9$ in year 1 to $€ 615.0 \pm 783.4$ in year 2 and $€ 481.0 \pm 676.2$ in year 3 . Hospitalisation costs were incurred by a quarter to a fifth of patients, representing under $10 \%$ of costs in each year. The mean hospitalisation cost per patient was $€ 498.4 \pm 1318.9$ in year 1 , $€ 526.2 \pm 1325.7$ in year 2 and $€ 423.3 \pm 1100.8$ in year 3 . Medical workups were consistently the smallest component of health resource utilisation, never exceeding $5 \%$ of yearly costs.

\section{Productivity losses}

Approximately a third of patients (30.1\%) incurred productivity losses in year 1 ; this decreased to a quarter of patients in year $2(23.4 \%)$ and year $3(24.4 \%)$. The mean cost of productivity losses was $€ 843.4 \pm 2899.1$ in

Table 2 Cost components as proportion of total costs by year of follow-up and biologics use

\begin{tabular}{llcrrr}
\hline Patient group & Cost component & Year 1 (\%) & Year 2 (\%) & Year 3 (\%) & Three-year total (\%) \\
\hline All patients $(\mathrm{n}=708)$ & Health practitioners & 15 & 11 & 10 & 12 \\
& Medical workups & 5 & 4 & 3 & 4 \\
& Hospitalisations & 10 & 10 & 9 & 9 \\
& Biologics & 50 & 59 & 66 & 58 \\
& All drugs & 54 & 61 & 68 & 61 \\
& Productivity loss & 17 & 14 & 10 & 14 \\
& All costs excluding & 50 & 41 & 34 & 42 \\
biologics & & & & \\
Ever received a biologic $(\mathrm{n}=225)$ & Health practitioners & 8 & 7 & 5 & 7 \\
& Medical acts & 4 & 2 & 2 & 3 \\
& Hospitalisations & 6 & 5 & 3 & 5 \\
& Biologics & 67 & 74 & 81 & 74 \\
& All drugs & 69 & 75 & 82 & 76 \\
Never received a biologic & Productivity loss & 13 & 10 & 7 & 10 \\
$(\mathrm{n}=483)$ & All costs excluding & 33 & 26 & 19 & 26 \\
& biologics & & & & \\
& Health practitioners & 33 & 29 & 29 & 31 \\
& Medical acts & 9 & 8 & 9 & 9 \\
& Hospitalisations & 22 & 26 & 32 & 26 \\
& Biologics & 0 & 0 & 0 & 0 \\
& All drugs & 8 & 7 & 8 & 7 \\
& Productivity loss & 28 & 29 & 22 & 27 \\
& All costs excluding & 100 & 100 & 100 & 100 \\
& biologics & & & & \\
& & & &
\end{tabular}


year $1, € 768.9 \pm 3368.0$ and $€ 497.0 \pm 1951.0$ in year 3 . In year 1 , productivity losses represented $16.8 \%$ of total costs, compared to $14.1 \%$ of total costs in year 2 and $10.0 \%$ of total costs in year 3 .

\section{Total costs}

The mean annual total cost per patient was $€ 5004.1$ \pm 6870.2 in year $1, € 5444.1 \pm 7936.9$ in year 2 and $€ 4960.6$ \pm 7457.4 in year 3 . Mean annual total costs rose with biologic use: patients who did not receive a biologic had mean total costs of $€ 1867.9 \pm 3056.6$ in year $1, € 1628.2$ \pm 3090.3 in year 2 and $€ 1292.9 \pm 2059.6$ in year 3 , compared to $€ 11736.4 \pm 7882.6$ in year $1, € 13635.4 \pm 8915.1$ in year 2 and $€ 12833.9 \pm 8667.4$ in year 3 among patients who received a biologic. In all years, biologics represented over $50 \%$ of total costs, up to $66.3 \%$ in year 3. Overall, the mean 3-year total cost among patients was $€ 15$ 408.7 \pm 19 793.5. Patients who never received a biologic had mean 3-year total costs of $€ 4789.04 \pm 6021.8$ compared to $€ 38205.74 \pm 19829.3$ among those who received a biologic. The estimated total costs in the

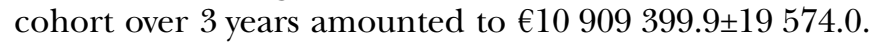
Of this, patients who received a biologic accounted for an estimated $€ 8596291.6 \pm 4860.9$ or $78.8 \%$ of all costs in the cohort. Figure 1 compares the trends in costs over the study period overall and for patients who received and did not receive a biologic.

\section{Factors associated with costs}

\section{Total costs}

In the final model (table 3), each month of biologics use was associated with a $23 \%$ increase (rate ratio (RR): 1.23; $95 \%$ CI 1.21 to 1.24 ) in total costs. The presence of peripheral arthritis at baseline was associated with a 19\% increase (RR: 1.19 ; 95\% CI 1.04 to 1.37 ) in total costs, while every 10-point increase in the average BASFI score was associated with an $18 \%$ increase in total costs (RR: $1.18 ; 95 \%$ CI 1.15 to 1.22 ). Although absolute costs were higher in year 2 than year 1 (table 4 ), when

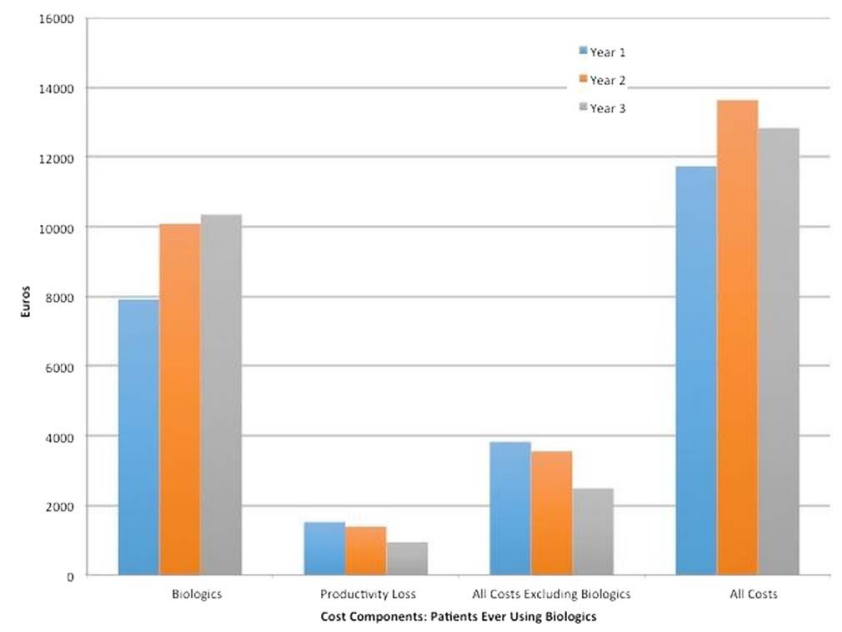

Figure 1 Yearly costs among biologics users. adjusting for time on biologics, costs in years 2 and 3 were significantly lower than in year 1 (table 3 ). Imaging status was not significantly associated with total costs and was excluded from the final model (figure 2).

\section{Cost excluding biologics}

In the final model (table 3), each month of biologics use was associated with a $4 \%$ increase (RR: $1.04 ; 95 \%$ CI 1.02 to 1.05$)$ in non-biologic costs. The presence of peripheral arthritis at baseline was associated with a $20 \%$ increase (RR: 1.20; 95\% CI 1.02, 1.40) in non-biologics costs; every 10-point increase in the average BASDAI score was associated with a $21 \%$ increase in non-biologic costs (RR: 1.21; 95\% CI 1.16 to 1.25). Every 5-year increase in age was associated with a $10 \%$ increase (RR: 1.10; $95 \%$ CI 1.05 to 1.16) in non-biologic costs, while males had $31 \%$ less costs relative to females (RR: 0.69; $95 \% 0.58$ to 0.81 ). Imaging status was not significantly associated with costs excluding biologics and was excluded from the final model.

\section{DISCUSSION}

This study described costs related to health resource utilisation and work productivity losses among patients with early SpA over 3 years. Our findings reflect the cost impact of biologics, which represented by far the largest cost component among DESIR patients. In the prebiologic era among patients with AS, work productivity loss was observed to account for the majority of total costs, for example, from $62 \%$ of total annual costs among patients with AS in Hong Kong ${ }^{24}$ to $74 \%$ of total annual costs among patients with AS in the UK. ${ }^{25}$ In our study, an analysis of patients with early SpA in the biologic era, productivity loss may be expected to represent a lower proportion of costs given patients' better functional status and higher drug costs; that said, productivity loss costs among DESIR patients still represented between $10 \%$ and $17 \%$ of annual costs over the study period. In terms of absolute costs, work productivity loss costs among DESIR patients (which ranged from $€ 843$ in year one to $€ 497$ in year 3) are consistent with those in a Dutch cohort of patients with early SpA (approximately $€ 422$ over 1 year). ${ }^{26}$ We note that our estimates of productivity loss costs are conservative: we did not calculate the costs of presenteeism, that is, the cost of reduced performance at work, which is another potentially important source of costs. ${ }^{27}$

Currently, there is increased interest in nonradiographic axial $\mathrm{SpA}$, defined as $\mathrm{SpA}$ in the absence of definite sacroiliac changes on X-ray, which includes both patients who satisfy only the clinical criteria for SpA and those with active inflammation in the sacroiliac joints visible only on MRI. ${ }^{28}$ To the best of our knowledge, this is the first longitudinal study of patients with SpA that has explored the impact of radiographic damage on cost, distinguishing between damage on X-Ray with or without MRI inflammation. Interestingly, 


\begin{tabular}{|c|c|c|c|c|c|c|c|c|c|c|c|}
\hline Outcome & Variable & $\begin{array}{l}\text { Rate ratio }(95 \% \\
\mathrm{Cl})\end{array}$ & p Value & Estimate & SE & $\begin{array}{l}\text { Estimate } \\
\text { lower } \\
\text { bound }\end{array}$ & $\begin{array}{l}\text { Estimate } \\
\text { upper } \\
\text { bound }\end{array}$ & $\begin{array}{l}\text { Min. } \\
\text { estimate }\end{array}$ & $\begin{array}{l}\text { Max. } \\
\text { estimate }\end{array}$ & $\begin{array}{l}\text { Minimum } \\
\text { rate ratio }\end{array}$ & $\begin{array}{l}\text { Maximum } \\
\text { rate ratio }\end{array}$ \\
\hline \multirow[t]{7}{*}{ Total costs } & $\begin{array}{l}\text { Age at baseline } \\
\text { (every 5-year } \\
\text { increase) }\end{array}$ & $1.06(1.02$ to 1.11$)$ & 0.006 & 0.060 & 0.022 & 0.017 & 0.102 & 0.055 & 0.065 & 1.06 & 1.07 \\
\hline & Male vs female & 0.75 (0.65 to 0.87$)$ & 0.000 & -0.287 & 0.074 & -0.432 & -0.142 & -0.304 & -0.265 & 0.74 & 0.77 \\
\hline & $\begin{array}{l}\text { Time on biologics } \\
\text { (in months) }\end{array}$ & $1.23(1.21$ to 1.24$)$ & $<0.0001$ & 0.205 & 0.005 & 0.195 & 0.216 & 0.205 & 0.205 & 1.23 & 1.23 \\
\hline & Year 2 vs year 1 & 0.89 (0.78 to 1.01$)$ & 0.063 & -0.119 & 0.064 & -0.244 & 0.007 & -0.125 & -0.114 & 0.88 & 0.89 \\
\hline & Year 3 vs year 1 & 0.71 (0.63 to 0.81$)$ & $<0.0001$ & -0.339 & 0.062 & -0.462 & -0.217 & -0.367 & -0.321 & 0.69 & 0.73 \\
\hline & $\begin{array}{l}\text { Average BASFI } \\
\text { score (every } \\
10 \text {-point increase) }\end{array}$ & 1.18 (1.15 to 1.22$)$ & $<0.0001$ & 0.168 & 0.015 & 0.137 & 0.198 & 0.164 & 0.172 & 1.18 & 1.19 \\
\hline & $\begin{array}{l}\text { Presence of } \\
\text { peripheral arthritis } \\
\text { at baseline }\end{array}$ & 1.19 (1.04 to 1.37$)$ & 0.014 & 0.177 & 0.072 & 0.036 & 0.318 & 0.166 & 0.198 & 1.18 & 1.22 \\
\hline \multirow[t]{7}{*}{$\begin{array}{l}\text { Non-biologic } \\
\text { costs }\end{array}$} & $\begin{array}{l}\text { Age at baseline } \\
\text { (every 5-year } \\
\text { increase) }\end{array}$ & $1.10(1.05$ to 1.16$)$ & 0.000 & 0.097 & 0.025 & 0.047 & 0.147 & 0.092 & 0.104 & 1.10 & 1.11 \\
\hline & Male vs female & 0.69 (0.58 to 0.81$)$ & $<0.0001$ & -0.377 & 0.087 & -0.548 & -0.206 & -0.398 & -0.349 & 0.67 & 0.71 \\
\hline & $\begin{array}{l}\text { Time on biologics } \\
\text { (in months) }\end{array}$ & 1.04 (1.02 to 1.05$)$ & $<0.0001$ & 0.037 & 0.008 & 0.022 & 0.052 & 0.037 & 0.038 & 1.04 & 1.04 \\
\hline & Year 2 vs year 1 & $0.87(0.75$ to 1.00$)$ & 0.050 & -0.143 & 0.073 & -0.286 & 0.000 & -0.151 & -0.139 & 0.86 & 0.87 \\
\hline & Year 3 vs year 1 & 0.72 (0.63 to 0.83$)$ & $<0.0001$ & -0.327 & 0.072 & -0.470 & -0.184 & -0.357 & -0.301 & 0.70 & 0.74 \\
\hline & $\begin{array}{l}\text { Average BASDAI } \\
\text { score (every } \\
\text { 10-point increase) }\end{array}$ & $1.21(1.16$ to 1.25$)$ & $<0.0001$ & 0.187 & 0.019 & 0.151 & 0.224 & 0.185 & 0.192 & 1.20 & 1.21 \\
\hline & $\begin{array}{l}\text { Presence of } \\
\text { peripheral arthritis } \\
\text { at baseline }\end{array}$ & $1.20(1.02$ to 1.40$)$ & 0.024 & 0.181 & 0.080 & 0.024 & 0.338 & 0.170 & 0.198 & 1.18 & 1.22 \\
\hline
\end{tabular}

Table 3 Models of total cost and non-biologic costs

at baseline 
Table 4 Health resource use and productivity loss costs in 2013 Euros by year of follow-up and biologics use

\begin{tabular}{|c|c|c|c|c|c|c|c|c|c|c|c|c|c|c|c|c|c|}
\hline \multirow[b]{2}{*}{ Patient group } & \multirow[b]{2}{*}{$\begin{array}{l}\text { Resource } \\
\text { component }\end{array}$} & \multicolumn{4}{|l|}{ Year 1} & \multicolumn{4}{|l|}{ Year 2} & \multicolumn{4}{|l|}{ Year 3} & \multicolumn{4}{|c|}{ Three-year total } \\
\hline & & $\begin{array}{l}\% \text { patients } \\
\text { with costs }\end{array}$ & Mean & SD & Med & $\begin{array}{l}\% \text { patients } \\
\text { with costs }\end{array}$ & Mean & SD & Med & $\begin{array}{l}\% \text { patients } \\
\text { with costs }\end{array}$ & Mean & SD & Med & $\begin{array}{l}\% \text { patients } \\
\text { with costs }\end{array}$ & Mean & SD & Med \\
\hline \multirow[t]{8}{*}{$\begin{array}{l}\text { All patients } \\
(n=708)\end{array}$} & $\begin{array}{l}\text { Health } \\
\text { practitioners* }\end{array}$ & 91 & 733 & 789 & 486 & 84 & 615 & 783 & 350 & 77 & 481 & 676 & 254 & 97 & 1829 & 1860 & 1239 \\
\hline & $\begin{array}{l}\text { Medical } \\
\text { workups } †\end{array}$ & 79 & 249 & 306 & 144 & 71 & 195 & 257 & 85 & 66 & 163 & 234 & 65 & 92 & 607 & 618 & 403 \\
\hline & Biologics & 24 & 2515 & 5322 & 0 & 27 & 3205 & 6202 & 0 & 26 & 3287 & 6460 & 0 & 32 & 9007 & 16512 & 0 \\
\hline & All drugs & 100 & 2680 & 5340 & 155 & 100 & 3339 & 6224 & 127 & 100 & 3396 & 6477 & 99 & 100 & 9416 & 16565 & 408 \\
\hline & HRU costs & 100 & 4161 & 5901 & 1297 & 100 & 4675 & 6780 & 1107 & 100 & 4464 & 6859 & 856 & 100 & 13299 & 17770 & 4505 \\
\hline & Productivity loss & 30 & 843 & 2899 & 0 & 23 & 769 & 3368 & 0 & 24 & 497 & 1951 & 0 & 46 & 2109 & 5846 & 0 \\
\hline & $\begin{array}{l}\text { All costs } \\
\text { excluding } \\
\text { biologics }\end{array}$ & 100 & 2489 & 3629 & 1228 & 100 & 2239 & 4159 & 872 & 100 & 1673 & 2718 & 706 & 100 & 6402 & 7770 & 3708 \\
\hline & All costs & 100 & 5004 & 6870 & 1547 & 100 & 5444 & 7937 & 1287 & 100 & 4961 & 7457 & 1063 & 100 & 15409 & 19794 & 5358 \\
\hline \multirow{8}{*}{$\begin{array}{l}\text { Ever received } \\
\text { a biologic } \\
(n=225)\end{array}$} & $\begin{array}{l}\text { Health } \\
\text { practitioners }^{*}\end{array}$ & 99 & 997 & 886 & 722 & 94 & 909 & 922 & 577 & 86 & 702 & 886 & 399 & 100 & 2608 & 2175 & 1952 \\
\hline & $\begin{array}{l}\text { Medical } \\
\text { workups } †\end{array}$ & 96 & 427 & 374 & 324 & 91 & 328 & 303 & 245 & 83 & 265 & 296 & 168 & 100 & 1020 & 716 & 922 \\
\hline & Biologics & 76 & 7913 & 6819 & 8510 & 86 & 10084 & 7191 & 12047 & 81 & 10344 & 7641 & 12694 & 100 & 28341 & 17606 & 28554 \\
\hline & All drugs & 100 & 8123 & 6802 & 8548 & 100 & 10265 & 7183 & 12186 & 100 & 10477 & 7650 & 12716 & 100 & 28865 & 17568 & 28962 \\
\hline & HRU costs & 100 & 10214 & 7073 & 11175 & 100 & 12244 & 7422 & 13437 & 100 & 11889 & 7895 & 13577 & 100 & 34347 & 17833 & 36107 \\
\hline & Productivity loss & 41 & 1523 & 3723 & 0 & 33 & 1391 & 4827 & 0 & 34 & 945 & 2900 & 0 & 59 & 3859 & 8071 & 485 \\
\hline & $\begin{array}{l}\text { All costs } \\
\text { excluding } \\
\text { biologics }\end{array}$ & 100 & 3823 & 4341 & 2019 & 100 & 3552 & 5614 & 1677 & 100 & 2490 & 3635 & 1217 & 100 & 9865 & 9727 & 6701 \\
\hline & All costs & 100 & 11736 & 7883 & 12477 & 100 & 13635 & 8915 & 13880 & 100 & 12834 & 8667 & 13765 & 100 & 38206 & 19829 & 39306 \\
\hline \multirow{8}{*}{$\begin{array}{l}\text { Never } \\
\text { received a } \\
\text { biologic } \\
(n=483)\end{array}$} & $\begin{array}{l}\text { Health } \\
\text { practitioners* }\end{array}$ & 88 & 610 & 707 & 352 & 80 & 478 & 668 & 211 & 72 & 378 & 522 & 177 & 95 & 1466 & 1566 & 937 \\
\hline & $\begin{array}{l}\text { Medical } \\
\text { workups† }\end{array}$ & 70 & 166 & 225 & 81 & 62 & 132 & 205 & 41 & 59 & 116 & 180 & 41 & 88 & 414 & 452 & 270 \\
\hline & Biologics & 0 & 0 & 0 & 0 & 0 & 0 & 0 & 0 & 0 & 0 & 0 & 0 & 0 & 0 & 0 & 0 \\
\hline & All drugs & 100 & 145 & 223 & 99 & 100 & 113 & 143 & 75 & 100 & 98 & 145 & 53 & 100 & 355 & 423 & 252 \\
\hline & HRU costs & 100 & 1341 & 1662 & 750 & 100 & 1149 & 1619 & 510 & 100 & 1004 & 1518 & 429 & 100 & 3495 & 3501 & 2240 \\
\hline & Productivity loss & 25 & 527 & 2360 & 0 & 19 & 479 & 2355 & 0 & 20 & 288 & 1241 & 0 & 40 & 1294 & 4206 & 0 \\
\hline & $\begin{array}{l}\text { All costs } \\
\text { excluding } \\
\text { biologics }\end{array}$ & 100 & 1868 & 3057 & 850 & 100 & 1628 & 3090 & 566 & 100 & 1293 & 2060 & 521 & 100 & 4789 & 6022 & 2633 \\
\hline & All costs & 100 & 1868 & 3057 & 850 & 100 & 1628 & 3090 & 566 & 100 & 1293 & 2060 & 521 & 100 & 4789 & 6022 & 2633 \\
\hline
\end{tabular}

*Health practitioners include physicians and other allied health professionals (nurse, physiotherapist, osteopath, etc).

†Medical workups include blood and urine tests, X-ray, ultrasound, scanner, MRI, bone densitometry, scintigraphy, respirometry, colonoscopy, mammography and fibroscopy. 


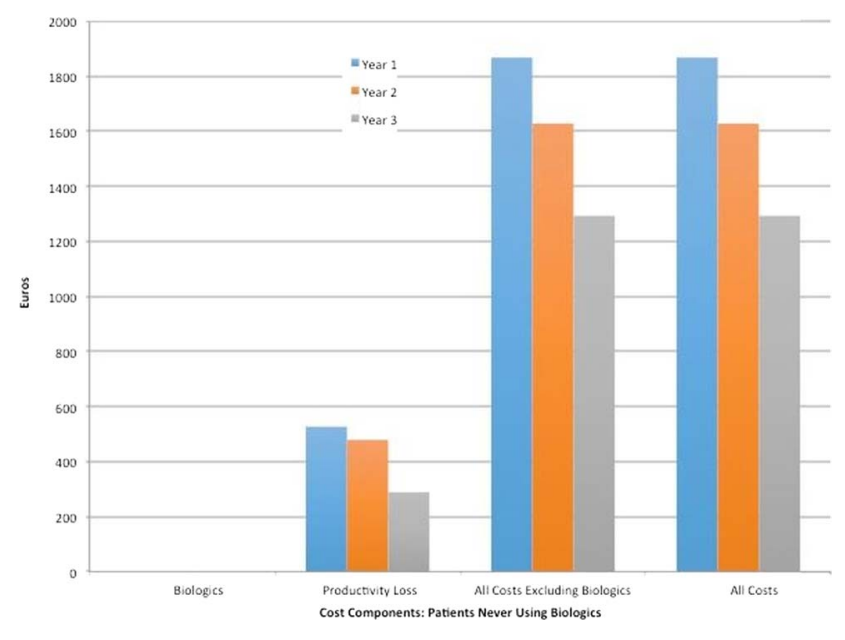

Figure 2 Yearly costs among non-biologics users.

while preventing progression to radiographic SpA remains a high priority from the clinical perspective, we found no significant independent effect of imaging status on total costs or costs excluding biologics.

In this study, the most significant cost component was biologic drugs, and patients who ever received a biologic accounted for over $75 \%$ of total costs in the cohort. While this was not surprising, the finding that approximately a quarter of DESIR patients had received a biologic by the 6-month visit (biologics use at baseline was not permitted ${ }^{9}$ ) was higher than anticipated, suggesting that biologics use was already relatively common even among patients with early SpA in 2010. Whether biologics provide good value for money is being explored in a separate study, which considers the impact of biologics on health-related quality of life. Our study also found peripheral arthritis, age and functional ability to be related to total costs, indicating subgroups where biologic use may be prioritised. In this study, we found that, in the first 3 years, treatment with biologics leads to increased costs in other health resource use domains, not a reduction as is sometimes expected; follow-up is needed to determine whether this trend holds over a longer period.

This study has some limitations. The DESIR cohort includes only patients with early SpA in France between 2007 and 2014; the results cannot necessarily be generalised to patients with $\mathrm{SpA}$ with more advanced disease or in other settings at other times. Indeed, it is unknown whether similarly high rates of biologic use exist among patients with early $\mathrm{SpA}$ in other countries; another recently established early SpA cohort ('SPACE') is ongoing in the Netherlands, ${ }^{29}$ but to the best of our knowledge the prevalence of biologics use in this cohort has not as yet been reported. A recent Canadian study of patients with SpA seen clinically between 2003 and 2014 found that $48 \%$ had been treated with a biologic, yet the mean disease duration (8 years) was much longer in this sample than in DESIR. ${ }^{30}$ Generalisable to patients with early SpA in France, our findings will allow for future comparisons with other cohorts of patients with early SpA, as well as the observation of trends within DESIR over time.

In terms of costing methods employed, we did not include non-SpA-related drugs, transportation or presenteeism, or include other patient out-of-pocket costs. Attendance declined over time and data imputation was required. Resource utilisation was self-reported and the potential exists for either underreported or overreported utilisation. In order to exclude the excess resource utilisation associated with study participation, we excluded the baseline visit from cost estimates. However, study participation could have also resulted in underestimation of resource utilisation following the baseline visit, if study visits replaced normal resource utilisation but were not reported as such. Finally, work productivity losses were estimated using self-reported workdays lost (rather than hours lost) and average daily wages by professional category, estimated from the entire population of French workers. We used profession-specific daily wages and did not further adjust wages for age and sex, although there are small differences in the age and sex distribution in DESIR compared to the French working population from which income data were derived $(48 \%$ female and $77 \%$ aged 25-54 among French workers vs 54\% female and $81 \%$ aged $25-54$ in DESIR ${ }^{31}$ ). By not adjusting for the $6 \%$ higher proportion of females in DESIR, it could be argued that we have slightly overvalued productivity losses, as daily wages among females in France are lower than among males; however, we note that wage inequality functions more generally to minimise the value of productivity loss. Although our valuation method provides a good estimate of productivity losses, we acknowledge that a greater level of accuracy could be achieved with direct self-report data on wage and productivity losses expressed in hourly terms. Despite these limitations, our findings are consistent with another recent description of patients with early $\mathrm{SpA}^{26}$ and reflect patterns of health resource utilisation and work productivity loss within one of the largest early SpA cohorts to date.

\section{Author affiliations}

${ }^{1}$ University of British Columbia, Vancouver, British Columbia, Canada ${ }^{2}$ Centre for Health Evaluation and Outcome Sciences, Vancouver, British Columbia, Canada

${ }^{3}$ Sorbonne Universités, UPMC Univ Paris 06, Paris, France

${ }^{4}$ Faculty of Medicine, University Paris Diderot, Paris, France

${ }^{5}$ AP-HP, Rheumatology Department, Lariboisiere University Hospital, Paris, France

${ }^{6}$ AP-HP, Rheumatology B Department, Cochin University Hospital, Paris, France

${ }^{7}$ Faculty of Medicine, University Paris Descartes, Paris, France

${ }^{8}$ EULAR Center of Excellence

${ }^{9}$ Clinical Epidemiology and Biostatistics, INSERM (U1153): PRES Sorbonne Paris-Cité, Paris, France

${ }^{10} \mathrm{AP}-\mathrm{HP}$, Rheumatology Department, Pitié Salpétrière University Hospital, Paris, France

Acknowledgements The authors acknowledge Sabrina Dadoun, Violaine Foltz, Fanny Roure, Guillaume Bertrand and Huiying Sun. The DESIR cohort is conducted under the control of Assistance publique-Hopitaux de Paris via the 
Clinical Research Unit Paris-Centre and under the umbrella of the French Society of Rheumatology and Inserm (Institut national de la santé et de la recherche médicale). The database management is performed within the department of epidemiology and biostatistics (Professor Jean-Pierre Daurès, D.I.M., Nîmes, France). An unrestricted grant from Wyeth Pharmaceuticals was allocated for the first 5 years of the follow-up of the recruited patients. We also wish to thank the different regional participating centres: Pr Maxime Dougados (Paris-Cochin B), Pr André Kahan (Paris-Cochin A), Pr Olivier Meyer (Paris-Bichat), Pr Pierre Bourgeois (Paris-La Pitié-Salpetrière), $\mathrm{Pr}$ Francis Berenbaum (Paris-Saint Antoine), Pr Pascal Claudepierre (Créteil), Pr Maxime Breban (Boulogne Billancourt), Dr Bernadette Saint-Marcoux (Aulnay-sous-Bois), Pr Philippe Goupille (Tours), Pr Jean-Francis Maillefert (Dijon), Dr Xavier Puéchal (Le Mans), Pr Daniel Wendling (Besancon), Pr Bernard Combe (Montpellier), Pr Liana Euller-Ziegler (Nice), Pr Philippe Orcel (Paris-Lariboisière), Pr Pierre Lafforgue (Marseille), Dr Patrick Boumier (Amiens), Pr Jean-Michel Ristori (Clermont- Ferrand), Dr Nadia Mehsen (Bordeaux), Pr Damien Loeuille (Nancy), Pr René-Marc Flipo (Lille), Pr Alain Saraux (Brest), Pr Corinne Miceli (Le Kremlin Bicêtre), Pr Alain Cantagrel (Toulouse), Pr Olivier Vittecoq (Rouen).

Contributors SH collected the economic data, cleaned and merged the clinical and economic data sets, undertook the costing methods described, developed the economic models, and drafted the manuscript. DG led the data management effort, provided expert statistical input (both theoretical and in computer programming), and designed the economic models. NB made substantial contributions to the development of methods, economic aspects of model development, and the interpretation of results. PR made substantial contributions to the conception of the work and acquisition of data. MD made substantial contributions to the conception of the work, the acquisition of data, clinical aspects of model development, and the interpretation of results. AA made substantial contributions to the design of the work, economic aspects of model development, and the interpretation of results. BF led the development of costing methods, the conception and design of the work, and contributed substantially to the acquisition of data, model development and the interpretation of results. All authors reviewed the work and revised it critically for important intellectual content. All authors give final approval of the version published and agree to be accountable for all aspects of the work in ensuring that questions related to the accuracy or integrity of any part of the work are appropriately investigated and resolved.

Funding The DESIR cohort is financially supported by unrestricted grants from both the French Society of Rheumatology and Pfizer Ltd, France.

Competing interests None declared.

Ethics approval University of British Columbia Research Ethics Board.

Provenance and peer review Not commissioned; externally peer reviewed.

Data sharing statement Additional unpublished data from this study are available to peer reviewers from the researchers on request.

Open Access This is an Open Access article distributed in accordance with the Creative Commons Attribution Non Commercial (CC BY-NC 4.0) license, which permits others to distribute, remix, adapt, build upon this work noncommercially, and license their derivative works on different terms, provided the original work is properly cited and the use is non-commercial. See: http:// creativecommons.org/licenses/by-nc/4.0/

\section{REFERENCES}

1. Baraliakos X, Braun J. Spondyloarthritides. Best Pract Res Clin Rheumatol 2011;25:825-42.

2. Rudwaleit $M$, Haibel $H$, Baraliakos $X$, et al. The early disease stage in axial spondylarthritis: results from the German Spondyloarthritis Inception Cohort. Arthritis Rheum 2009;60:717-27.

3. Zink A, Thiele K, Huscher D, et al. Healthcare and burden of disease in psoriatic arthritis. A comparison with rheumatoid arthritis and ankylosing spondylitis. J Rheumatol 2006;33:86-90.

4. Barlow JH, Wright CC, Williams $\mathrm{B}$, et al. Work disability among people with ankylosing spondylitis. Arthritis Rheum 2001;45:424-9.

5. Boonen $\mathrm{A}$, Chorus $\mathrm{A}$, Miedema $\mathrm{H}$, et al. Withdrawal from labour force due to work disability in patients with ankylosing spondylitis. Ann Rheum Dis 2001;60:1033-9.
6. Palla I, Trieste L, Tani C, et al. A systematic literature review of the economic impact of ankylosing spondylitis. Clin Exp Rheumatol 2012;30:S136-41.

7. Reveille JD, Ximenes A, Ward MM. Economic considerations of the treatment of ankylosing spondylitis. Am J Med Sci 2012;343:371-4.

8. Dougados M, d'Agostino MA, Benessiano J, et al. The DESIR cohort: a 10-year follow-up of early inflammatory back pain in France: study design and baseline characteristics of the 708 recruited patients. Joint Bone Spine 2011;78:598-603.

9. Dougados $\mathrm{M}$, Etcheto $\mathrm{A}$, Molto $\mathrm{A}$, et al. Clinical presentation of patients suffering from recent onset chronic inflammatory back pain suggestive of spondyloarthritis: The DESIR cohort. Joint Bone Spine 2015;82:345-51.

10. Calin A, Porta J, Fries JF, et al. Clinical history as a screening test for ankylosing spondylitis. JAMA 1977;237:2613-4.

11. Rudwaleit M, Metter A, Listing J, et al. Inflammatory back pain in ankylosing spondylitis: a reassessment of the clinical history for application as classification and diagnostic criteria. Arthritis Rheum 2006;54:569-78.

12. Caisse Nationale de l'Assurance Maladie (France). L'Assurance Maladie en Ligne. 25 February 2014. http://www.ameli.fr/assures/ soins-et-remboursements/combien-serez-vous-rembourse/ consultations/les-consultations-en-metropole/dans-le-cadre-duparcours-de-soins-coordonnes.php

13. Institut de recherche et de documentation en économie de la santé. Institut de recherche et de documentation en économie de la santé. 28 July 28 2014. http://www.irdes.fr

14. Institut de recherche et de documentation en économie de la santé. Eco-Santé Base de Données en Licence Ouverte. April 2014, 2014. http://www.ecosante.fr/index2.php?base=FRAN\&langh=FRA\&langs= FRA\&sessionid=

15. Vidal Group. Dictionnaire Vidal: L'information de référence sur les produits de santé. http://vidalfrance.com

16. Sécurité Sociale L'Assurance Maladie. Medic'AM. 16 February 2015. http://www.ameli.fr/l-assurance-maladie/statistiques-et-publications/ donnees-statistiques/medicament/medic-am-2008-2012.php

17. Agence Technique de l'Information sur l'Hospitalisation. Utilisation des codes diagnostics principaux ou actes classants dans les bases. 2013. http://stats.atih.sante.fr/mco/catalogmco.php

18. Agence Technique de l'Information sur l'Hospitalisation. Tarifs MCO et HAD. 2013. http://www.atih.sante.fr/?id=0001000021FFmorey

19. [Anonymous]. Inflation.eu: Worldwide inflation data. Triami Media BV. http://www.inflation.eu/inflation-rates/france/historic-inflation/cpiinflation-france.aspx

20. National Institute of Statistics and Economic Studies. Publications et statistiques pour la France ou les régions. http://www.insee.fr/fr/ themes/theme.asp?theme $=4$

21. Pan W. Akaike's information criterion in generalized estimating equations. Biometrics 2001;57:120-5.

22. Shen $\mathrm{CW}$, Chen $\mathrm{YH}$. Model selection of generalized estimating equations with multiply imputed longitudinal data. Biom $J$ 2013;55:899-911.

23. IMORI S. Model selection criterion based on the multivariate quasilikelihood for generalized estimating equations. Scand J Stat 2015;42:1214-24.

24. Zhu TY, Tam LS, Lee VW, et al. Costs and quality of life of patients with ankylosing spondylitis in Hong Kong. Rheumatology (Oxford) 2008:47:1422-5.

25. Ward MM. Functional disability predicts total costs in patients with ankylosing spondylitis. Arthritis Rheum 2002;46:223-31.

26. van der Weijden MA, Boonen A, van der Horst-Bruinsma IE. Problems in work participation and resource use should not be underestimated in patients with early spondyloarthritis. $J$ Rheumatol 2014;41:2413-20.

27. Boonen A, Brinkhuizen T, Landewé R, et al. Impact of ankylosing spondylitis on sick leave, presenteeism and unpaid productivity, and estimation of the societal cost. Ann Rheum Dis 2010;69:1123-8.

28. Boonen A, Sieper J, van der Heijde D, et al. The burden of nonradiographic axial spondyloarthritis. Semin Arthritis Rheum 2015;44:556-62.

29. van den Berg R, de Hooge M, Rudwaleit M, et al. ASAS modification of the Berlin algorithm for diagnosing axial spondyloarthritis: results from the SPondyloArthritis Caught Early (SPACE)-cohort and from the Assessment of SpondyloArthritis international Society (ASAS)cohort. Ann Rheum Dis 2013;72:1646-53.

30. Bedaiwi M, Sari I, Thavaneswaran A, et al. Fatigue in ankylosing spondylitis and nonradiographic axial spondyloarthritis: analysis from a longitudinal observation cohort. J Rheumatol 2015;42:2354-60.

31. Institut National de la statistique et des études économiques. Emploi- Population Active. http://www.insee.fr/fr/mobile/etudes/ document.asp?reg_id=0\&ref_id=T13F041 